\title{
Relationship between Tropical Easterly Waves and Precipitation during the North American Monsoon
}

\author{
WILLIAM C. LADWIG \\ Cooperative Institute for Mesoscale Meteorological Studies, University of Oklahoma, and NOAA/National Severe \\ Storms Laboratory, Norman, Oklahoma \\ DAVID J. STENSRUD \\ NOAA/National Severe Storms Laboratory, Norman, Oklahoma
}

(Manuscript received 14 September 2007, in final form 3 July 2008)

\begin{abstract}
Relationships between tropical easterly waves (TEWs) and precipitation over Mexico and the United States are examined during the North American monsoon (NAM). The National Centers for Environmental Prediction-National Center for Atmospheric Research reanalysis data are used to identify 137 TEWs that cross Mexico north of $20^{\circ} \mathrm{N}$ after monsoon onset over a 31-yr period from 1975 to 2005. Mean precipitation anomalies over two-day periods both before and after TEW passage are determined using Climate Prediction Center daily precipitation analyses. Results indicate that positive precipitation anomalies occur along the west coast of Mexico and extending into the west-central United States in association with TEW passage. Negative precipitation anomalies are found in the south-central United States. These precipitation anomaly patterns share many similarities to precipitation anomaly patterns previously defined in association with gulf surge events. On longer time scales, correlations between the total number of these northern TEWs crossing Mexico and 90-day monsoon period precipitation anomalies are also examined. An out-of-phase relationship is found between monsoon period precipitation anomalies in the southwestern and south-central United States, suggesting that increasing the number of northern TEWs crossing Mexico leads to enhanced monsoon period rainfall in Arizona and New Mexico and reduced monsoon period rainfall in Texas and Oklahoma. Thus, these northern TEWs likely play an important role in producing the distribution of precipitation throughout the NAM region and the south-central United States during the monsoon season, and extendedrange predictions of northern TEW frequency may lead to improved seasonal rainfall anomaly forecasts in these regions.
\end{abstract}

\section{Introduction}

During the summer months of July, August, and September, the semiarid regions of the southwestern United States and northwestern Mexico experience a wet season commonly referred to as the North American monsoon (NAM). The NAM is responsible for $60 \%-80 \%$ of the annual precipitation in northwest Mexico and $40 \%$ of the annual precipitation in the southwestern United States (Douglas et al. 1993). The main precipitation region is along the western slopes of the Sierra Madre Occidental Mountains in western Mexico (Fig. 1).

Corresponding author address: Dr. David J. Stensrud, National Severe Storms Laboratory, National Weather Center, 120 David L. Boren Blvd., Norman, OK 73072.

E-mail: david.stensrud@noaa.gov
The NAM is often divided into an early season, which affects the southwestern portion of Mexico from the middle of May through early July, and a late season from July through mid-September, which affects northwestern Mexico and the southwestern United States (Higgins et al. 1999; Gutzler 2004). During the late season when the monsoon is at its peak, rainfall rates typically exceed $2 \mathrm{~mm}$ day $^{-1}$ throughout much of the monsoon region, with a small area in south-central Mexico exceeding $8 \mathrm{~mm}$ day $^{-1}$. The northern portion of the NAM is defined as the core monsoon region by Gutzler (2004) as it experiences the most interannual rainfall variability.

The primary source of moisture for the NAM is the Gulf of California (Hales 1972, 1974; Brenner 1974; Stensrud et al. 1995). Although studies have observed the presence of diurnal low-level jets over the Gulf of 


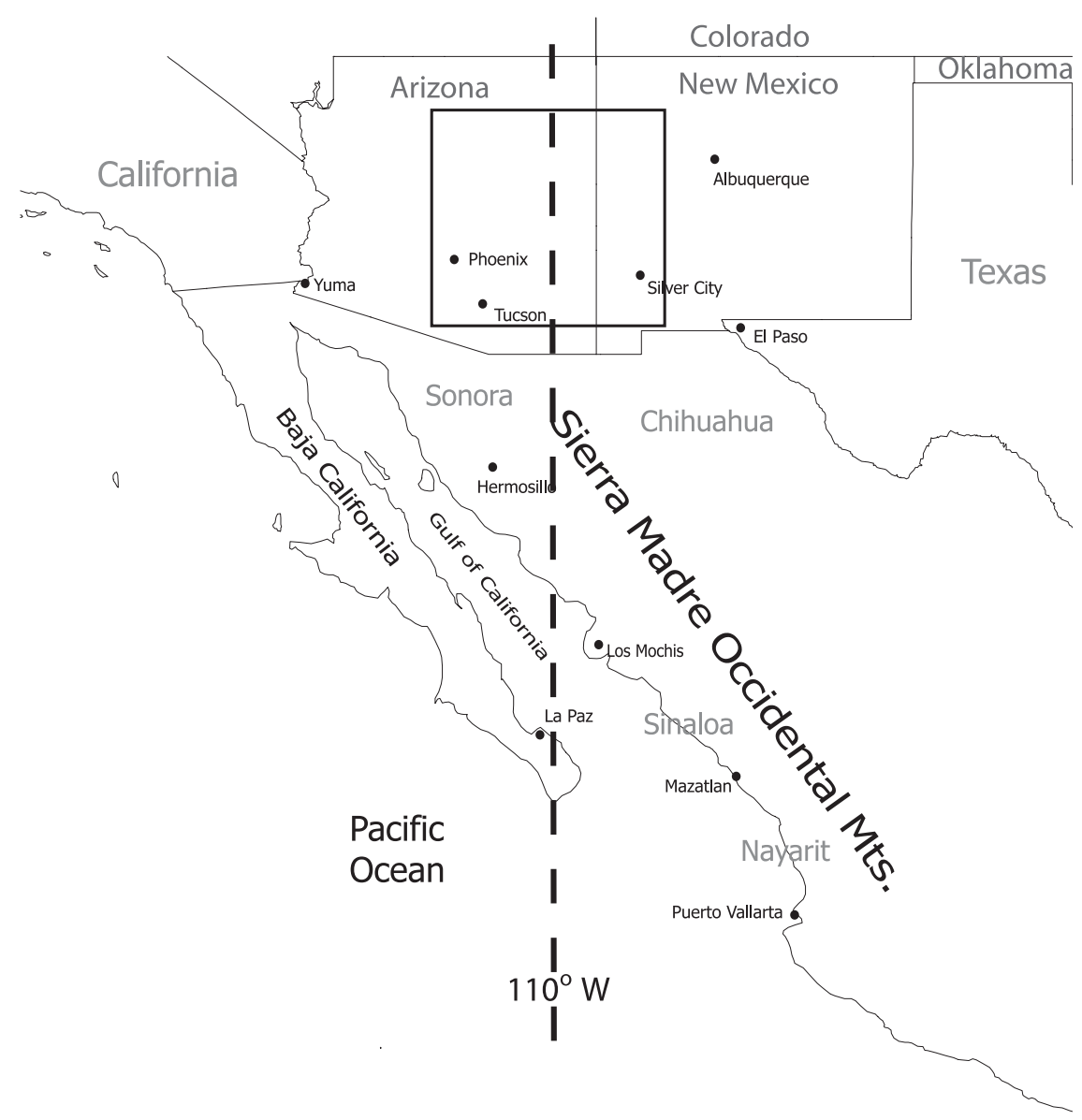

FIG. 1. Geography of the North American monsoon region. The AZNM region used to define monsoon onset is outlined by the rectangular box. Vertical dashed line indicates $110^{\circ} \mathrm{W}$.

California (Douglas 1995; Douglas et al. 1998; Bordoni et al. 2004), the most influential transport mechanism for the core monsoon region is the gulf surge (Hales 1972, 1974; Brenner 1974; McCollum et al. 1995; Stensrud et al. 1995, 1997; Fuller and Stensrud 2000; Douglas and Leal 2003; Rogers and Johnson 2007; Bordoni and Stevens 2006). A gulf surge is a coastally trapped wavelike disturbance that travels northward over the Gulf of California. Associated with this disturbance is an increase in dewpoint temperature, a decrease in air temperature, and strong southerly winds (Hales 1972; Brenner 1974). Gulf surges vary in intensity, and although several factors play a role in the initiation of a gulf surge, there is a strong connection between the initiation of gulf surges and the passage of tropical easterly waves (TEWs) across western Mexico (Hales 1972; Brenner 1974; Stensrud et al. 1997; Fuller and Stensrud 2000; Higgins et al. 2004, hereafter HSH04). Approximately $75 \%$ of gulf surges are associated with the passage of a TEW across western Mexico near $20^{\circ} \mathrm{N}$ (Fuller and Stensrud 2000). However, the intensity of precipitation associated with a gulf surge is strongly influenced by the location of the upper-level anticyclone over North America, with relatively wet surges occurring when the midlatitude anticyclone is located to the east of the NAM region (HSH04). The northward extent of NAM rainfall is also greatly influenced by gulf surges (Bordoni and Stevens 2006), further emphasizing the important role that this transient mesoscale phenomenon plays in defining the characteristics of the NAM.

Anomalous precipitation patterns from the days before and after the passage of a gulf surge are examined by HSH04. Prior to surge onset, a dry anomaly exists over northwestern Mexico and the Great Plains. During surge onset, wet anomalies appear all along the western Mexican coast, with the largest anomalies over the core monsoon region. In the days following the gulf surge, positive precipitation anomalies occur over the northern core monsoon region and extend into Arizona, while the Great Plains is anomalously dry. Higgins and Shi (2005) show that surges related to eastern Pacific 
tropical cyclones tend to be associated with deeper and moister southerly low-level flow and higher rainfall totals over the core monsoon region of northwest Mexico.

The results of a number of previous studies (Tang and Reiter 1984; Douglas et al. 1993; Mock 1996; Mo et al. 1997; Higgins et al. 1997, 1998) further show that the precipitation pattern of the NAM region has an out-ofphase relationship with the precipitation regime over the Great Plains. Results suggest that increased NAM precipitation leads to a strengthened and expanded upper-level monsoon anticyclone over the southwestern United States, resulting in large-scale subsidence and reduced precipitation over the central United States (Higgins et al. 1998). However, another explanation for this out-of-phase precipitation pattern is suggested by Adams and Stensrud (2007). Given the same set of initial conditions, they perform four month-long simulations with and without TEWs represented in the model boundary conditions. Results indicate that the simulated TEWs act to reduce rainfall in the south-central United States by decreasing the northward moisture flux into this region while increasing rainfall over the northern NAM region. The decrease in northward moisture flux into the south-central United States is shown to occur as TEWs interrupt the mean low-level southerly flow while crossing the Gulf of Mexico. This hypothesis is further supported by Mo and Berbery (2004), who show that decreases in south-central U.S. rainfall are associated with reduced northward moisture flux near the Texas coast and weaker more easterly mean low-level flow over the Gulf of Mexico.

Unfortunately, the Adams and Stensrud (2007) study is limited in only examining four 1-month periods and the results based largely upon model simulations. If TEWs influence both NAM and south-central U.S. rainfall as suggested by the modeling study of Adams and Stensrud (2007), then this relationship should also be apparent in observational data. Thus, the goal of this study is to use observationally based datasets to explore the relationships between TEW passages across western Mexico and precipitation in the NAM and south-central U.S. regions.

The present study is divided into two distinct yet interrelated parts. The first part examines two-day precipitation anomalies that are keyed to the day of TEW passage across western Mexico. This analysis follows the same procedure as used in the analyses of HSH04 and Higgins and Shi (2005), but focuses upon the two-day precipitation anomalies due to TEWs instead of gulf surges. The second part of the data analysis explores the correlation between the number of TEWs that cross western Mexico north of $20^{\circ} \mathrm{N}$ and precipitation anomalies during the 90-day period after the start of the monsoon season. This analysis examines the seasonal influence of all the observed TEWs on rainfall across North America to either support or refute the modeling results of Adams and Stensrud (2007). The data and methodology are discussed in sections 2 and 3. Results from the analyses are presented in sections 4 and 5, with a discussion and summary in sections 6 and 7 .

\section{Data}

The National Centers for Environmental PredictionNational Center for Atmospheric Research (NCEPNCAR) reanalysis data (Kalnay et al. 1996) are used to track TEWs for the $31 \mathrm{yr}$ between 1975 and 2005. The data are available at 6-h increments and at a horizontal grid spacing of $2.5^{\circ} \times 2.5^{\circ}$. The parameters used from this dataset are the meridional wind, zonal wind, and geopotential height at $600 \mathrm{hPa}$. While the $700-\mathrm{hPa}$ level often is used to analyze TEWs (Reed et al. 1977; Fuller and Stensrud 2000), $600 \mathrm{hPa}$ is found to be the level that yields the most consistent TEW tracks in this study. The tracking of TEWs is conducted throughout the region between $10^{\circ}$ and $120^{\circ} \mathrm{W}$ longitude and $5^{\circ}$ and $35^{\circ} \mathrm{N}$ latitude. Although the years between 1958 and 1975 are available, the years prior to 1975 are particularly noisy over the oceans because of the absence of satellite data (Kalnay et al. 1996). Results (not shown) indicate that the number of clearly defined waves prior to 1975 is rather limited and the exclusion of these early years from the analysis does not influence the final results.

Daily Climate Prediction Center (CPC) precipitation analyses at a horizontal resolution of $1^{\circ} \times 1^{\circ}$ and valid at 1200 UTC are used to define precipitation anomalies across the United States and Mexico from 1975 to 2005. The daily rainfall analyses are produced by HSH04 as a merger of the CPC Unified Precipitation Dataset (Higgins and Shi 2000) with daily rain gauge data over Mexico. Precipitation data for the United States are obtained from approximately 2500 stations, whereas precipitation data for Mexico are obtained from 300 stations prior to the 1990s and approximately 600 stations in more recent years. This combined dataset is gridded using a modified Cressman (1959) analysis scheme (Glahn et al. 1985; Charba et al. 1992). This unified dataset has been used in previous studies of the NAM (HSH04; Higgins and Shi 2005; Adams and Stensrud 2007). Precipitation anomalies are defined as the departure from the 19712000 mean daily rainfall totals to be consistent with Higgins et al. (1997) and HSH04 and are calculated for each grid point. To compare our results with these previous studies, precipitation anomalies are summed over two-day periods relative to the day that TEWs pass across western Mexico. 


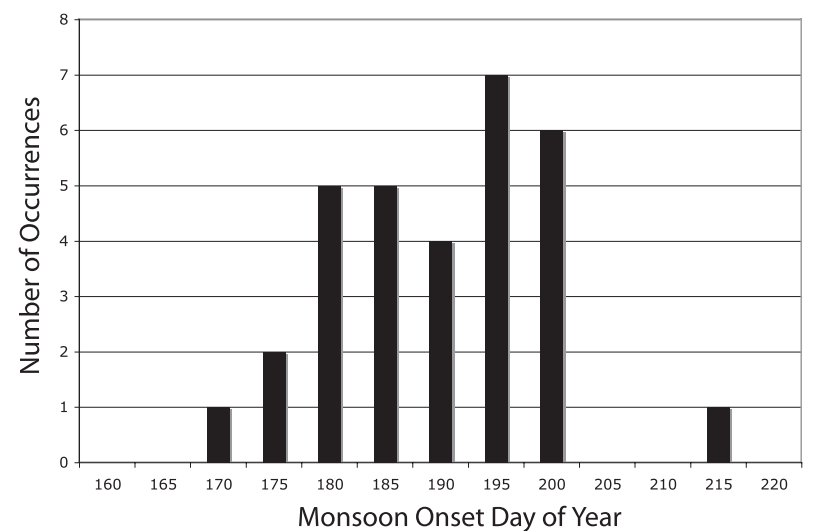

FIG. 2. Histogram of monsoon onset days (yearday) binned into 5-day intervals. For reference, day 170 is 19 Jun, day 190 is $9 \mathrm{Jul}$, and day 215 is 3 Aug for nonleap years.

Since rainfall over the core NAM region can begin as early as mid-June or as late as August, it is important to restrict the analyses only to periods when the NAM is active. Following Higgins et al. (1997), this can be done by determining the monsoon onset date for the ArizonaNew Mexico (AZNM) region of the monsoon using a precipitation index (PI). The PI is calculated by averaging daily accumulations of observed precipitation (at each grid point) in the rectangular region $\left(32^{\circ}-36^{\circ} \mathrm{N}\right.$, $113^{\circ}-108^{\circ} \mathrm{W}$ ) over Arizona and western New Mexico (Fig. 1). The monsoon onset date is defined as the first day after 1 June when the PI is above $+0.5 \mathrm{~mm}_{\text {day }}{ }^{-1}$ for three consecutive days.

The monsoon period is defined as the 90-day period following the monsoon onset date (Higgins et al. 1998). A 90-day time period is chosen because it is sufficiently long to encompass the most of the NAM duration and, with an average TEW frequency of three per month, ensures that the interannual variability in TEW frequency is captured. However, a disadvantage of this methodology is that if the monsoon onset date is late in the summer (day 195 or greater), the 90-day time period extends past the typical end date of the monsoon in midSeptember (Fig. 2). This situation occurs in $22 \%$ of the monsoon seasons analyzed.

To explore the linkages between the number of TEWs and North American rainfall, 90-day monsoon period precipitation anomalies are calculated for each of the $31 \mathrm{yr}$ from 1975 to 2005. However, as each monsoon period's anomaly is defined relative to the mean 1971-2000 precipitation over the monsoon period (which varies since the monsoon onset dates are different for each year), the average precipitation anomaly calculated from this approach is not necessarily zero and the anomalies are influenced by the monsoon onset date. Thus, to isolate the interannual signal associated with TEWs, the average monsoon period precipitation is calculated over all 31 monsoon periods and subtracted from the precipitation amounts of each individual year's monsoon period. Using this approach the monsoon period precipitation anomalies have a zero mean by definition.

\section{Methodology}

\section{a. Identification of northern TEWs}

Tropical easterly waves are synoptic-scale disturbances that develop in the easterlies over tropical northern Africa near the prime meridian. They have wavelengths of $2000-4000 \mathrm{~km}$, propagate westward at 6-9 $\mathrm{m} \mathrm{s}^{-1}$, and are best defined in the low-to-midtroposphere (Burpee 1972, 1974; Reed et al. 1977). TEWs develop in the latitude belt from $10^{\circ}$ to $30^{\circ} \mathrm{N}$ (Burpee 1974; Fyfe 1999; Chen 2006) and can move slowly northward or southward within this belt as they cross the Atlantic (see Pasch et al. 1998; Pytharoulis and Thorncroft 1999). Observations of TEW passages across western Mexico by Douglas and Leal (2003) indicate that large wave amplitudes often occur between $15^{\circ}$ and $25^{\circ} \mathrm{N}$. Fink et al. (2004) further indicate that TEW activity over Africa near $20^{\circ} \mathrm{N}$ can be quite strong in June and July in contrast to the southern waves near $10^{\circ} \mathrm{N}$ that become more active later in the summer.

Tropical easterly wave passage in NAM studies is often determined using Hovmöller diagrams of the meridional wind component over the Atlantic Ocean (Fuller and Stensrud 2000; HSH04; Adams and Stensrud 2007; Bordoni and Stevens 2006). In these studies, the trough of the TEW is located where the meridional wind changes from northerly to southerly. Wavelengths between 2000 and $4000 \mathrm{~km}$ are required to help eliminate non-TEW disturbances in the wind field that have a similar appearance to a TEW on a Hovmöller diagram. However, a common occurrence when tracking TEWs on these diagrams is that the TEW signal becomes complex over landmasses and island chains as the TEW interacts with topography (Bordoni and Stevens 2006), generally beginning in the region near the Caribbean and extending westward over Mexico. To track the TEWs in these regions of more complicated meridional wind patterns, the TEW trough location may be extrapolated on a Hovmöller diagram by linearly connecting the known wave trough locations to the east and west of landmasses (dashed lines in Fig. 3).

Unfortunately, identifying the time of TEW passage across western Mexico using a Hovmöller diagram with reanalysis data is difficult [see discussions of the 


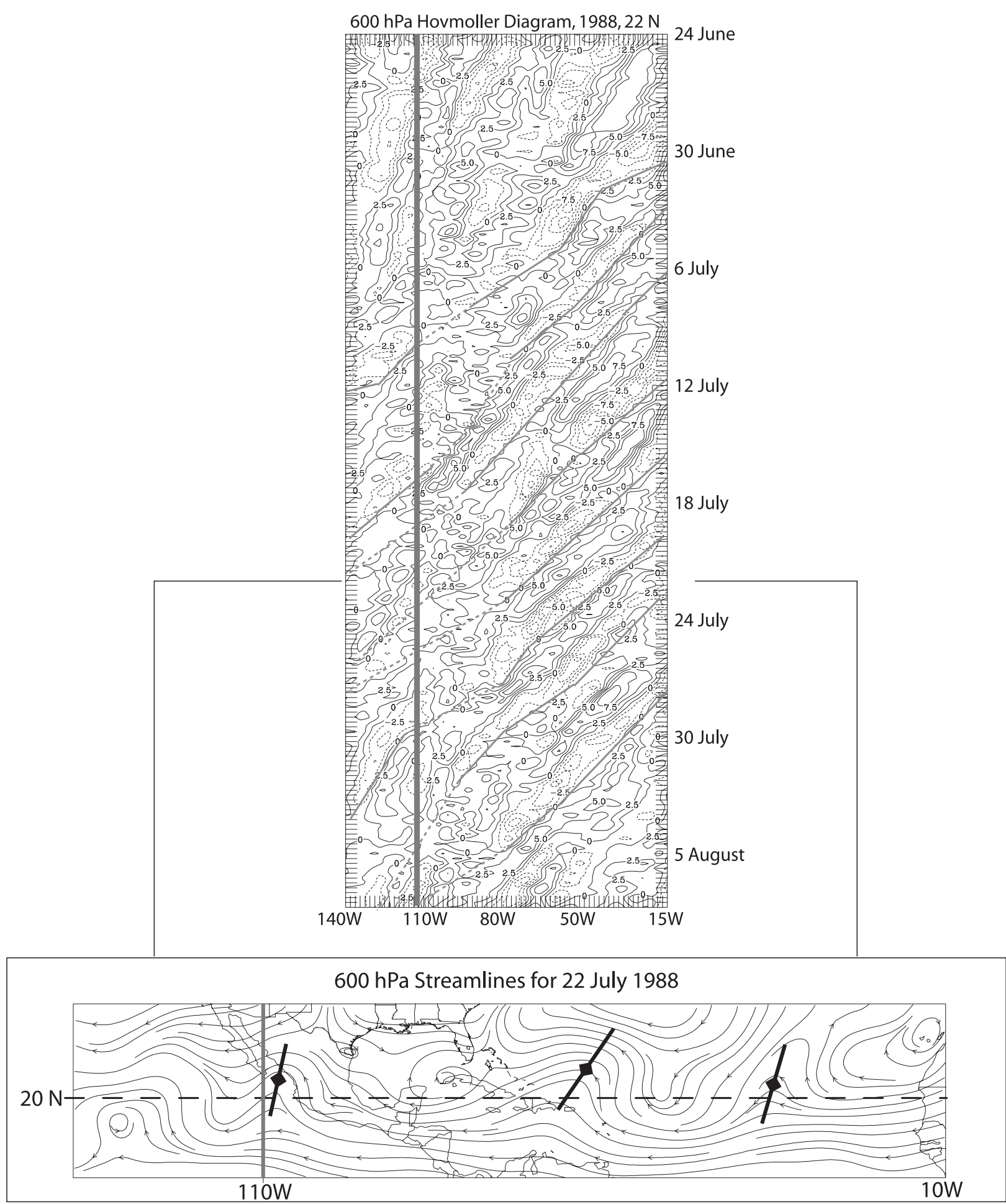

FIG. 3. Hovmöller diagram at $22^{\circ} \mathrm{N}$ latitude for 1988 along with 600-hPa streamlines for northern TEWs on 22 Jul. For the Hovmöller diagram, isolines of northerly (dashed) and southerly (solid) wind speeds $\left(\mathrm{m} \mathrm{s}^{-1}\right)$ are shown every $2.5 \mathrm{~m} \mathrm{~s}^{-1}$ and $110^{\circ} \mathrm{W}$ is indicated by the vertical thick gray line. TEW trough axes are indicated by thick solid lines, while dashed lines indicate where TEW trough axes are extrapolated. For the streamline plot, the dashed horizontal line indicates $20^{\circ} \mathrm{N}$ latitude and the thick gray vertical line indicates $110^{\circ} \mathrm{W}$. The $110^{\circ} \mathrm{W}$ longitude line is used to define the day of northern TEW passage across western Mexico. Diamonds indicate the TEW trough midpoints. 
challenges to tracking TEWs in Fink et al. (2004) and Chen (2006)]. The TEW phase speeds prove to be inconsistent (Fig. 3), and in several cases the northern portion of a wave travels at a slower speed than the southern portion, leaving two waveforms on the plot. This unsteady westward progression of TEWs is also seen in Berry and Thorncroft (2005), who find that TEW accelerations, decelerations, and retrogressions occur in response to deep convection. Since using Hovmöller diagrams alone is not always sufficient to identify the day during which a TEW crosses western Mexico, streamline and vorticity plots are used as additional analysis tools, as suggested by Berry et al. (2007). Streamlines are useful for identifying noise in the wind field, which is generally in the form of small cyclonic eddies. The streamline plots are also useful for diagnosing other nonwave disturbances such as tropical cyclones.

Although the streamline plots provide a better representation of the wind field, tracking TEWs is still a challenging task because of the background noise and the complicated structure of the waves themselves. Thorncroft and Hodges (2001) find that vorticity can be used effectively as a filter to eliminate small amplitude waves and noise in these types of analyses. Thus, in this study a TEW must maintain a relative vorticity contour of at least $0.5 \times 10^{-5} \mathrm{~s}^{-1}$ at $600 \mathrm{hPa}$ for a time period of 3 days in order for a wave to be tracked and counted. This vorticity filter is applied visually by examining both the vorticity field and streamlines concurrently.

Owing to all the challenges involved in accurately tracking TEWs, and the need to determine the day of TEW passage across western Mexico, Hovmöller diagrams, streamline plots, and vorticity fields are all used to identify and track TEWs in the present study. The three plot types are generated for each 90-day monsoon period during the $31 \mathrm{yr}$ from 1975 to 2005 . The daily streamline and vorticity fields (generated at 0000 UTC) are animated and TEWs are tracked visually from the coast of Africa westward across the Atlantic and over Mexico. Thus, all the TEWs in this study originate over Africa. Results from this analysis are then compared to the results obtained from a Hovmöller diagram that also extends eastward to the coast of Africa. A consensus is obtained in the event the two analyses do not match, favoring the Hovmöller diagram if the wind field is noisy and favoring the streamlines if the phase speed is inconsistent.

Since this study is focused upon the effects of TEWs on NAM and south-central U.S. precipitation, TEWs that propagate entirely south of $20^{\circ} \mathrm{N}$ are neglected since they are not related to gulf surge development as suggested by the studies of Fuller and Stensrud (2000), Douglas and Leal (2003), and HSH04. Thus, only northern TEWs, defined as having a sharp northerly to southerly meridional wind shift north of $20^{\circ} \mathrm{N}$ that resumes in the eastern Pacific following their interaction with the topography over Mexico, are considered. As an example, the streamlines at $600 \mathrm{hPa}$ for 22 July 1988 show two TEWs over the Atlantic with an average wavelength of $3100 \mathrm{~km}$ and a third TEW located over western Mexico (Fig. 3). All three of these TEWs are clearly observed to extend north of $20^{\circ} \mathrm{N}$, yet can be tracked backward in time to the West African coast. Wavelike disturbances that show a closed circulation in the trough on streamline analyses south of the Gulf of California are excluded, as are waves that rapidly develop into closed circulations (e.g., tropical cyclones) south of the Gulf of California. As shown by Farfan and Zehnder (2001), tropical cyclones that make landfall in western Mexico or the southwest United States can produce significant rainfall totals. The inclusion of these events in the present study would bias the results and so are avoided. However, any northern TEWs that develop closed circulations after crossing $110^{\circ} \mathrm{W}$ longitude are included. It is important to note that the strict guidelines in this analysis may prevent several northern TEWs from being counted, as the purpose is to identify only the most clearly defined TEWs north of $20^{\circ} \mathrm{N}$.

The day of northern TEW passage across western Mexico is defined as the day in which the midpoint of the TEW trough passes $110^{\circ} \mathrm{W}$ (Fig. 3). Since many TEWs tilt from southwest to northeast (Burpee 1974), the southern portion of the wave may pass over the Gulf of California region while the northern portion of the wave is still over central Mexico (Douglas and Leal 2003). For the more highly tilted TEWs (e.g., the northern TEW just entering into the Caribbean in Fig. 3) the length of time between the southern and northern extents of the TEW trough passing a given longitude can be several days. This observation is important to the interpretations of the resulting two-day precipitation anomalies, since gulf surges likely are initiated as the southern portion of the TEW first begins to cross the Gulf of California.

A total of 137 northern TEWs are tracked during the 31 monsoon periods from 1975 to 2005, with results indicating a maximum of 7 waves and a minimum of 2 waves, corresponding with a mean of 4.4 waves and a standard deviation of 1.3 waves. This wave count is in rough agreement with the climatology of TEWs (inverted troughs) shown in Douglas and Englehart (2007). They count the number of days that various features influence a $20^{\circ}$ longitude zone over northern Mexico and the southern United States from June through September. Converting these day counts into an estimate for the total mean number of TEWs in a 


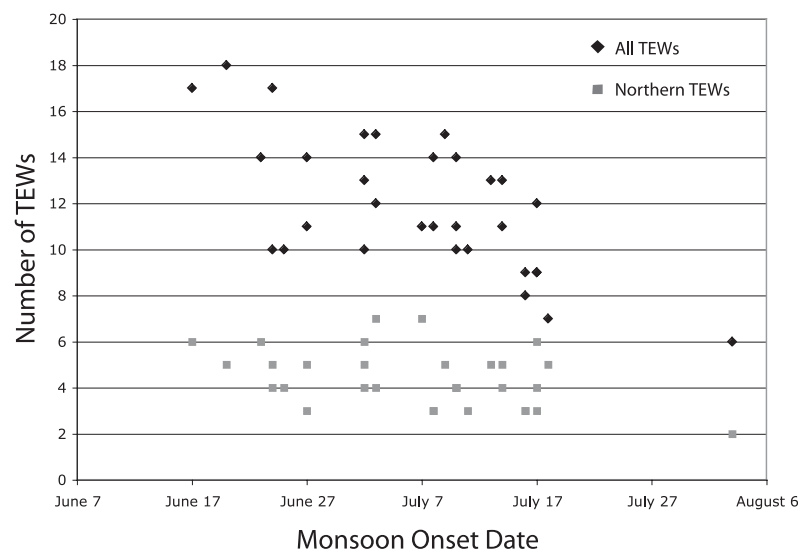

FIG. 4. The number of TEWs crossing Mexico vs monsoon onset date for northern TEWs (gray squares) and for all TEWs (black diamonds).

90-day monsoon period yields an estimate of 17 TEW days, which converts into 4 to 6 TEWs depending upon their assumed phase speed.

A plot of the number of northern TEWs versus monsoon onset date shows that the number of northern TEWs in each 90-day monsoon period does not appear to be influenced by the monsoon onset date (Fig. 4). However, the total number of TEWs that cross $110^{\circ} \mathrm{W}$ without regard to latitude decreases fairly linearly as the monsoon onset date increases (Fig. 4), perhaps because more TEWs develop into more organized tropical systems as the summer progresses.

\section{b. Significance testing for correlation results}

Significance testing is performed on the correlations between the TEW counts and the 90-day monsoon period precipitation anomalies in section 5 by first reducing the degrees of freedom in the dataset using the methodology described by Chen (1982). For $N$ samples, the formula for the effective degrees of freedom $n$ is given by

$$
n=\frac{N \Delta t}{\tau} \leq N,
$$

where $\Delta t$ is the sampling time, and the effective time $\tau$ between independent samples is estimated using

$$
\tau=\sum_{i=-\infty}^{\infty} C_{W W}(i \Delta t) C_{R R}(i \Delta t) \Delta t,
$$

where $C_{W W}$ is the autocorrelation of the yearly TEW counts and $C_{R R}$ is the autocorrelation of the yearly 90-day monsoon period rainfall anomalies at lags $i \Delta t$.

Correlations $r$ between the TEW counts and 90-day monsoon period rainfall anomalies at each grid point are transformed using the Fisher transform (Wilks 1995):

$$
z^{*}=\frac{1}{2} \ln \left(\frac{1+r}{1-r}\right),
$$

where the distribution of $z^{*}$ approximates a Gaussian distribution with a mean of 0 and a standard deviation of $(n-3)^{-1 / 2}$ under the null hypothesis that $r$ is equal to 0 . To determine if a correlation value is locally significant to the $95 \%$ confidence level, the value $z *$ is compared to the value $z$ given by

$$
z=\frac{1.96}{\sqrt{n-3}},
$$

where $n$ is the effective degrees of freedom calculated using (1). A correlation value is locally significant where the absolute value of $z^{*}$ is greater than $z$. It is also important to note that using the $t$ value of 2.052 instead of 1.96 in (4) yields no significant difference in the results presented.

The methodology of Livezey and Chen (1983) is used with a few modifications to determine spatial field significance. First, the local significance test above is applied to the actual dataset and the number of significant data points for the region of interest is tabulated. Next, the northern TEW count data are randomly shuffled and the correlation values computed using the randomly shuffled TEW data as the first variable and the monsoon period precipitation anomaly data as the second variable. Local significance testing is performed with these correlation values and the number of significant data points recorded. This procedure is repeated for 102000 shuffles. Spatial field significance is determined by counting the times that the number of significant points for the actual northern TEW data exceeds the number of significant points for the randomly shuffled TEW data. This field significance test is first performed using all grid points within the United States and Mexico and then performed over smaller regions of local significance (e.g., New Mexico and Arizona).

\section{Precipitation anomalies}

Precipitation anomalies keyed to the passage of the 137 northern TEWs between 1975 and 2005 are calculated to compare with the results of HSHO4 and Higgins and Shi (2005), who keyed precipitation anomalies to gulf surge event onset. The day of TEW passage across western Mexico (day 0, defined as the day when the midpoint of the wave trough crosses $110^{\circ} \mathrm{W}$ ), is determined as outlined in section 3 , and the total precipitation anomalies for two-day periods relative to this date 

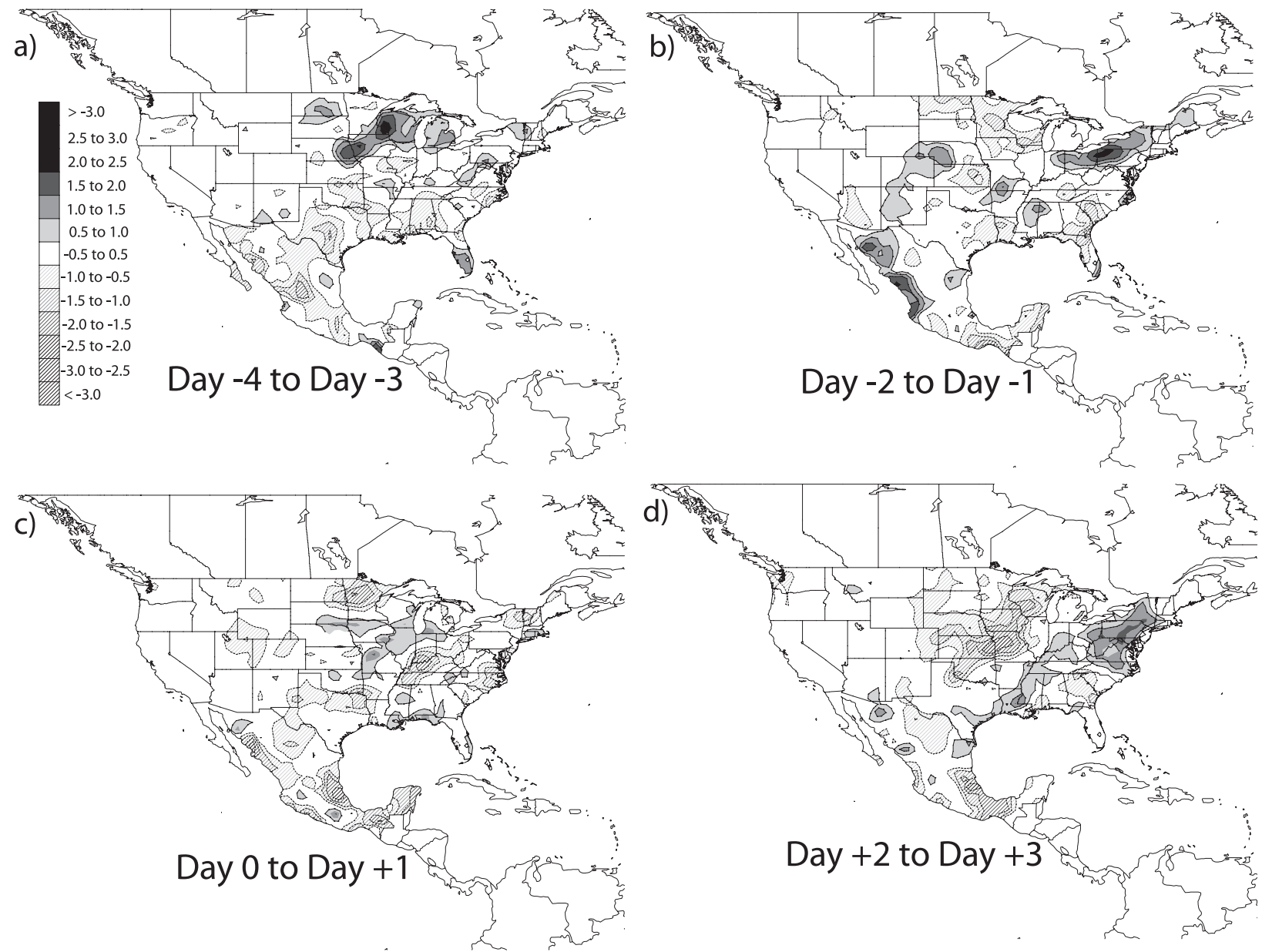

FIG. 5. Composite evolution of two-day precipitation anomalies $(\mathrm{mm})$ associated with the passage of northern TEWs across $110^{\circ} \mathrm{W}$ for (a) day -4 to day -3 , (b) day -2 to day -1 , (c) day 0 to day +1 , and (d) day +2 to day +3 . Positive anomalies are shaded solid and negative anomalies are shaded with lines. The contour interval is $0.5 \mathrm{~mm}$. The days indicate the days relative to northern TEW passage across $110^{\circ} \mathrm{W}$, with negative values indicating days preceding wave passage and positive values indicating days after wave passage.

are determined. Two-day time periods are chosen to examine the anomalous precipitation associated with TEWs because they provide the best separation between the anomalous precipitation patterns, without having to use hourly precision for the timing of wave passage. Thus, two-day periods help to keep the wave effects reasonably isolated from each other. The twoday periods examined are day -4 to day -3 , day -2 to day -1 , day 0 to day +1 , and day +2 to day +3 .

\section{a. Day -4 to day -3}

Prior to the passage of the northern TEW across western Mexico, negative precipitation anomalies are located over nearly all of Mexico, the south-central United States (Texas, Oklahoma, and Kansas), and much of the southeastern United States (Fig. 5a). Florida experiences a positive anomaly, which may be related to the position of the TEW over the Caribbean. These same anomaly patterns are seen in the precipitation anomalies keyed to all gulf surge events during the day -4 to day -2 period (HSH04), except that the precipitation anomalies keyed to gulf surge events are positive over southern Mexico. However, if the gulf surge precipitation anomalies are keyed only to gulf surges that are not related to tropical cyclones (Higgins and Shi 2005) or to weak gulf surge events (HSH04), the anomalies also are negative across much of Mexico in agreement with the pattern in Fig. 5a. Thus, the positive precipitation anomalies across southern Mexico found in association with gulf surges in $\mathrm{HSH04}$ likely are due to the influence of tropical cyclones (Higgins and Shi 2005).

\section{b. Day -2 to day -1}

During this time period, the midpoint of the TEW is over central Mexico, although the southern portion of the TEW may have already crossed the Gulf of 
California. A clear pattern of positive precipitation anomalies is evident to the west of the Sierra Madre Occidental Mountains from south-central Mexico northward through the core monsoon region and extending into New Mexico, Colorado, and Nebraska (Fig. 5b). Since upward motion can precede the TEW trough (Reed et al. 1977; Stensrud et al. 1997), the positive anomalies over Mexico and extending into New Mexico are likely due to convection ahead of the TEW trough. It is more difficult to argue persuasively that the positive anomalies farther north over Colorado and Nebraska are also linked to the approach of the TEW trough, although Douglas and Leal (2003) show that midlevel winds near $40^{\circ} \mathrm{N}$ are influenced by westerly moving tropical waves. Negative anomalies are evident over much of Arizona, as well as eastern Kansas, the upper Midwest, and portions of the Southeast. Large portions of southeastern Mexico are anomalously dry after TEW passage.

This pattern shares many features in common with the precipitation anomalies associated with all gulf surge events and weak gulf surge events for the day -1 to day +1 period (HSH04), including the positive anomalies along western Mexico and the negative anomalies in Arizona and the south-central United States. The zone of positive precipitation anomalies in Fig. 5b stretching northward from Mexico across New Mexico and Colorado also is suggested in the precipitation anomalies associated with gulf surge events not associated with tropical cyclones (Higgins and Shi 2005).

Differences are seen in the timing of the precipitation anomalies relative to northern TEW passage as shown in Fig. 5 and surge onset as reported in HSH04 and Higgins and Shi (2005). In general, positive anomalies in the NAM region are seen prior to northern TEW passage across $110^{\circ} \mathrm{W}$ in Fig. $5 \mathrm{~b}$ but only seen after surge onset. This difference is due to the different time scales of the phenomena examined and how the two phenomena are keyed to the precipitation data. As mentioned in section 3, the southwest-to-northeast tilt of TEWs indicates that the southern portion of the waves pass over the Gulf of California first and can thereby initiate a gulf surge up to several days prior to when the TEW trough midpoint crosses $110^{\circ} \mathrm{W}$. Thus, it is not unexpected that rainfall over western Mexico associated with northern TEWs occurs in the day -2 to day -1 time period. In contrast, surge onset does not occur until a surge reaches southern Arizona and so the positive rainfall anomalies over western Mexico occur near the time of surge onset.

\section{c. Day 0 to day +1}

In the time period closely following the passage of the northern TEW midpoint across Mexico (Fig. 5c), negative precipitation anomalies are present along the southern portion of the core monsoon region. However, a small region of positive precipitation anomalies persists in the northern portion of the core monsoon region in northwest Mexico. Negative anomalies stretch from central Mexico across western Texas and eastward into northern Louisiana. Positive precipitation anomalies occur in the Midwest and stretch southwesterly into Oklahoma. This pattern shares many features in common with precipitation anomalies associated with weak gulf surges for the day +2 to day +4 period ( $\mathrm{HSH} 04$ ), including the negative anomalies across much of Mexico and the south-central United States. However, the positive anomaly over northwest Mexico and Arizona is much larger and stronger when associated with all gulf surge events (HSH04) and gulf surge events related to tropical cyclones (Higgins and Shi 2005).

\section{d. Day +2 to day +3}

Two to three days following the passage of a TEW (Fig. $5 \mathrm{~d}$ ), a small positive precipitation anomaly is still evident over the northern portion of the core monsoon region and extending into Arizona. A region of negative anomalies is maintained over eastern Mexico that stretches northward into New Mexico. A broad region of negative anomalies also extends from north Texas into the midwestern states, with a band of positive anomalies stretching from southern Texas northeastward into New England. The positive anomalies over northwest Mexico and Arizona are again smaller and weaker compared to the anomalies found in association with gulf surge events.

While many of these patterns in Fig. 5 are similar to those of HSH04 and Higgins and Shi (2005), who examined precipitation anomalies in association with gulf surges observed entering into Arizona, the best agreement with Fig. 5 occurs for precipitation anomalies associated with weak gulf surges and for surges not related to tropical cyclones. This result further underscores the important role played by tropical cyclones in producing favorable environments for very strong surge events and in producing heavy rainfall over western Mexico and Arizona. However, the general evolution of precipitation anomalies during northern TEW passage clearly demonstrates that TEWs influence the precipitation patterns within the NAM region. The similarity between the precipitation anomalies over western Mexico when keyed to either TEW or surge passage further supports the linkage between TEWs and gulf surges as discussed in previous studies (Stensrud et al. 1997; Fuller and Stensrud 2000; HSH04; Bordoni and Stevens 2006). Further underscoring the importance of northern TEWs to NAM 
precipitation is the observation that the wet monsoons of Higgins et al. (1998) are associated with a mean of 5.3 northern TEW passages (calculated using only years after 1975), while dry monsoons are associated with a mean of 3.0 northern TEW passages.

The modeling results of Adams and Stensrud (2007) suggest that TEWs may expand the region of precipitation outward from the core monsoon region without increasing the total amount of precipitation that falls. The progression of the precipitation anomalies in association with northern TEW passage (Fig. 5) appears to be consistent with this hypothesis. As the positive precipitation anomalies expand into the northern monsoon region of Arizona and New Mexico, negative precipitation anomalies develop over the core monsoon region as well as much of eastern Mexico. Based on this coupling of positive and negative anomalies, the idea that TEWs act to redistribute the moisture within the monsoon region appears plausible.

The precipitation patterns over the south-central United States also appear to be influenced by the passage of northern TEWs, with negative precipitation anomalies seen across this region during several time periods. Previous studies show a seasonal out-of-phase relationship between the NAM region and Great Plains rainfall (Tang and Reiter 1984; Douglas et al. 1993; Mock 1996; Mo et al. 1997; Higgins et al. 1997, 1998) and an in-phase relationship with East Coast rainfall (Tang and Reiter 1984; Higgins et al. 1997, 1998). The intensity and location of the large-scale summertime monsoon anticyclone over North America is linked to the amount of NAM precipitation and exerts a fundamental control on summertime precipitation over the central United States (Higgins et al. 1998). However, based on the progression of the two-day precipitation anomalies presented here, it appears these phase relationships may also occur on shorter time scales in association with northern TEWs as suggested by Adams and Stensrud (2007).

\section{Out-of-phase precipitation relationship}

The hypothesis that the out-of-phase relationship between NAM and south-central U.S. precipitation is produced in part by northern TEWs is investigated using a correlation analysis. Correlations are calculated between the number of northern TEWs that cross Mexico during the 90-day monsoon period and the 90-day monsoon period precipitation anomalies for each grid point in the CPC precipitation dataset and each of the $31 \mathrm{yr}$ of data. Correlation values are calculated using the Pearson correlation formula. The northern TEW counts and monsoon period precipitation anomalies are correlated for the years of 1975 through 2005.
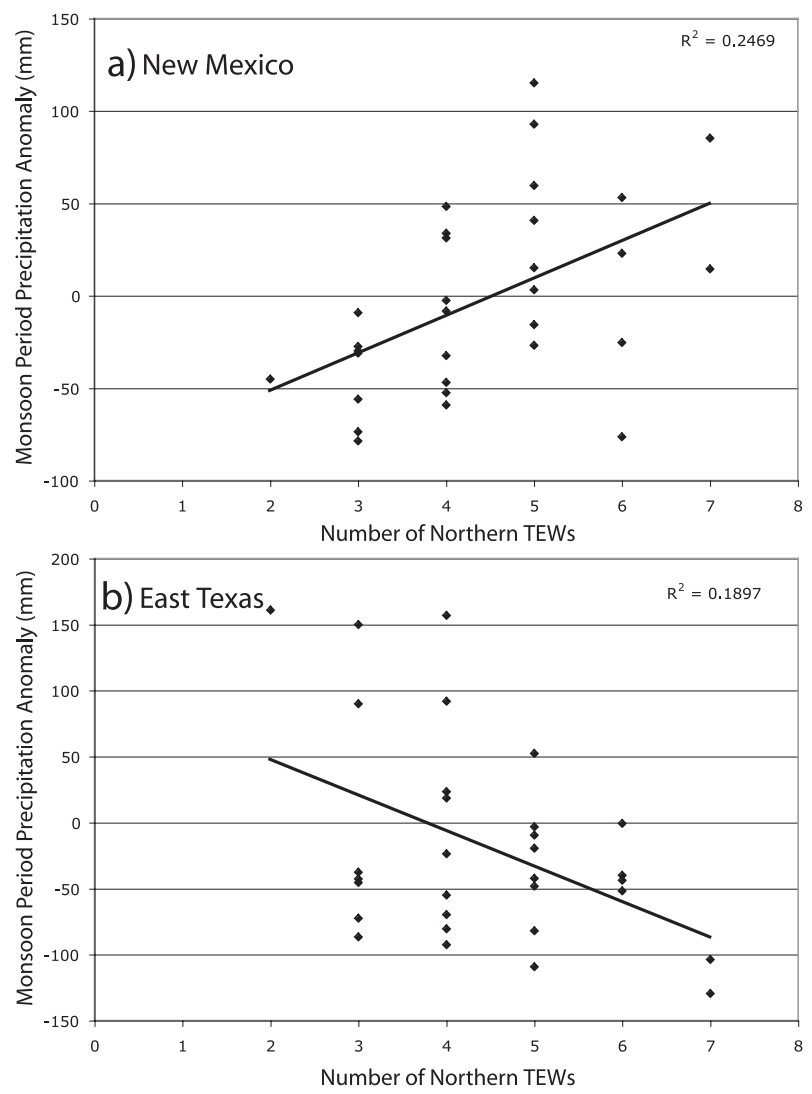

FIG. 6. Scatterplot of the 90-day monsoon period precipitation anomaly $(\mathrm{mm})$ vs the number of northern TEWs during this monsoon period for a point in (a) New Mexico and (b) eastern Texas.

To verify the linear assumption of the Pearson correlation results, scatterplots are generated at several geographic points of significant correlation (Fig. 6). The scatterplots indicate that, while the relationship between monsoon period precipitation anomalies and the number of northern TEWs shows a fair amount of variability, a linear assumption is probably acceptable. To be certain, rank correlations (Wilks 1995) are also generated by assigning ranks to the monsoon period precipitation anomaly and northern TEW data (assigning mean values to tied ranks) and passing these ranked values to the Pearson correlation formula. The results of the rank correlation are very similar to the Pearson correlation results and so are not discussed further.

Results show that a locally significant area of moderate $0.4-0.5$ positive correlation is evident in the border region between New Mexico and Arizona (Fig. 7), partially overlapping the positive day -2 to day -1 precipitation anomalies associated with northern TEW passage (Fig. 5b). A large region of locally significant negative correlation occurs over much of Texas and southern Oklahoma (Fig. 7), which again largely coincides 


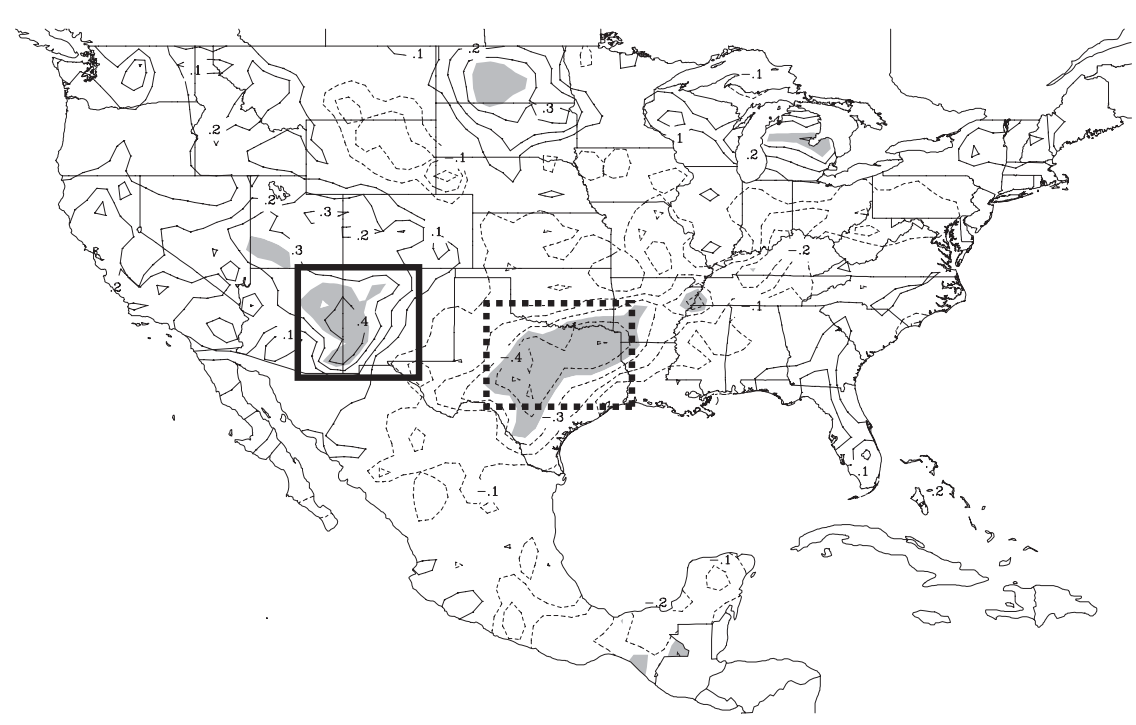

FIG. 7. Values of the Pearson correlation calculated between the number of northern TEWs that cross western Mexico during the 90-day monsoon period and the 90-day monsoon period precipitation anomalies. Locally significant regions are shaded. Solid rectangular region indicates where field significance test passes to a $95 \%$ confidence level. Dashed rectangular region indicates where field significance test passes to a $90 \%$ confidence level. Isolines every 0.1 with negative values dashed and the zero isoline omitted.

with the two-day negative precipitation anomalies associated with northern TEWs (Fig. 5). A few other areas of locally significant correlation exist across the United States, most notably in the far northern plains. Precipitation anomalies associated with gulf surges in HSHO4 and Higgins and Shi (2005) also show positive precipitation anomalies in the northern plains consistent with the results in Fig. 5.

In contrast to the correlation values in the southern United States, the correlation values over Mexico are small, suggesting that the number of northern TEWs that cross Mexico has little influence on the interannual NAM rainfall variability in this region. Since the number of rainfall stations in Mexico doubled after 1990, it may be that the distribution of rainfall data in the first $16 \mathrm{yr}$ of the analysis does not accurately represent NAM rainfall and contributes to this lack of correlation. It may also be that TEWs that cross Mexico farther to the south also influence NAM rainfall and hence the contributions from northern TEWs are only part of the total signal. In addition, $\mathrm{Hu}$ and Feng (2002) indicate that interannual monsoon rainfall variability in south-central Mexico is strongly influenced by variations in the location of the intertropical convergence zone.

\section{Discussion}

These correlation results and the precipitation anomalies of section 4 indicate that northern TEWs influence both the short-term two-day precipitation anomalies and the 90-day monsoon period precipitation anomalies over Arizona-New Mexico and the south-central United States in consistent ways. Perhaps most importantly, the spatial pattern of correlation (Fig. 7) is consistent with an out-of-phase relationship between NAM and southcentral U.S. rainfall (Higgins et al. 1997, 1998). While these correlation results fail to pass the Livezey and Chen (1983) field significance test when evaluating all the points in the United States and Mexico, by reducing the domain to the locally significant region in New Mexico and Arizona $\left(32^{\circ}-37^{\circ} \mathrm{N}, 112^{\circ}-105^{\circ} \mathrm{W}\right)$ the results pass with $95 \%$ confidence. The locally significant regions in the south-central United States fail at $95 \%$ but pass at $90 \%$. The same basic patterns are found with nearly identical correlation values and local significance levels if the TEW and rainfall data from 1971-2000 are used instead of the data from 1975-2005.

Although causality cannot be determined by correlation, these results are largely consistent with the modeling study of Adams and Stensrud (2007), where it is found that increasing the number of northern TEWs leads to increased rainfall in northwestern Mexico, Arizona, and New Mexico and reduced rainfall in the south-central United States. The correlation results presented here suggest that increasing the number of northern TEWs crossing western Mexico leads to increased rainfall in Arizona and New Mexico and reduced rainfall in the south-central United States. However, it 
may be that increasing the number of northern TEWs simply increases NAM precipitation, thereby strengthening the upper-level monsoon anticyclone and leading to reduced south-central U.S. precipitation via subsidence (Higgins et al. 1998). To explore this possibility, mean 200-hPa geopotential heights during the months of August and September are examined for all $31 \mathrm{yr}$ and the strengths (maximum geopotential heights) and locations of the mean upper-level monsoon anticyclone determined. Results (not shown) indicate that increasing the number of northern TEWs leads in the mean to a northeastward shift of the anticyclone location, although there is a large amount of variation. However, the number of TEWs has relatively little influence on the strength of the monsoon anticyclone with correlations between TEW count and anticyclone strength near zero or slightly negative. These results suggest that the effects of northern TEWs on the NAM likely cannot be explained solely by their affects on the upper-level monsoon anticyclone. Further study is needed to determine if the interruption of low-level moisture advection by northern TEWs is responsible for the reduction of south-central U.S. rainfall as proposed by Adams and Stensrud (2007). However, their hypothesis is consistent with the results of Mo and Berbery (2004) showing that meridional moisture flux is reduced over Texas and Oklahoma in association with anomalously dry precipitation anomalies over the south-central United States.

While these results are encouraging, the challenges involved in obtaining a highly accurate count of northern TEWs and the relatively short 31-yr dataset also are likely influencing the results presented. The number of northern TEWs per 90-day monsoon period typically ranges from 2 to 7 waves. Given the short length of the dataset and the relatively small number of waves, an error of $+/-1$ wave per year could affect the results.

\section{Summary}

Previous studies examine relationships between TEWs, gulf surges, and precipitation regimes over North America through both observations and model simulations (Stensrud et al. 1997; Fuller and Stensrud 2000; Douglas and Leal 2003; HSH04; Higgins and Shi 2005; Bordoni and Stevens 2006; Adams and Stensrud 2007). Results from these studies show that the passage of northern TEWs across western Mexico often can induce a gulf surge, which in turn affects the distribution of precipitation throughout the NAM region. To further explore the relationship between northern TEWs and precipitation, NCEP-NCAR reanalysis and CPC precipitation data are used to define two-day precipitation anomalies both prior to and after the passage of northern
TEWs across western Mexico. In addition, correlations between the number of northern TEWs crossing Mexico and 90-day monsoon period precipitation anomalies are examined.

To examine the influence of northern TEWs on precipitation anomalies throughout the monsoon region and the United States, 137 northern TEW cases are used to determine the mean anomalous two-day precipitation patterns before, during, and after the passage of a northern TEW across Mexico. Results show that rainfall over western and northwestern Mexico is greatly enhanced by the presence of a northern TEW, similar to the rainfall patterns associated with gulf surges (HSH04; Higgins and Shi 2005). The two-day precipitation anomalies show that precipitation is increased across New Mexico northward into Colorado and Nebraska and decreased over the south-central United States, in association with northern TEW passage. Over southern Mexico, the northern TEW two-day precipitation patterns lack the positive precipitation anomaly seen in the typical strong surge composite of HSH04 and for surges related to tropical cyclones (Higgins and Shi 2005). Since northern TEWs associated with tropical cyclones are omitted from the present study, this suggests that positive precipitation anomalies over southern Mexico are associated with the presence of tropical cyclones. Overall, the rainfall patterns associated with northern TEWs most closely resemble the weak surge composite of HSH04 and the surge composite for events not associated with tropical cyclones (Higgins and Shi 2005). These twoday precipitation anomaly results suggest that northern TEWs act to expand the region of precipitation outward from the core monsoon region without increasing the total amount of precipitation that falls, consistent with the modeling results of Adams and Stensrud (2007).

The geographic distribution of correlations between the number of northern TEWs that cross Mexico during the 90-day monsoon period and the 90-day monsoon period precipitation anomalies is also examined. Results indicate that increasing the number of northern TEWs leads to increased rainfall in Arizona and New Mexico and reduced rainfall in the south-central United States (Texas and southern Oklahoma). The correlations in these two areas range from 0.4 to 0.5 , and pass a field significance test at either $90 \%$ (south-central United States) or 95\% (Arizona and New Mexico) confidence. While the intensity and location of the upper-level monsoon anticyclone is known to play a significant role in the seasonal rainfall distribution over North America (Higgins et al. 1998), both the two-day precipitation anomalies and the 90-day monsoon period correlation results support the hypothesis of Adams and Stensrud (2007) that northern TEWs also play a role in 
producing the out-of-phase relationship between the NAM and south-central U.S. rainfall. Thus, extendedrange predictions of northern TEW frequency may be useful in helping to determine seasonal rainfall anomalies over these regions.

While the results of this study are supportive of the hypothesis that TEWs influence both south-central U.S. and NAM rainfall, further research is warranted. It is important to determine more clearly the mechanisms by which TEWs influence moisture flux into the southcentral United States. Greater knowledge of the typical frequency and structure of northern TEWs also is needed to better understand their interaction with the NAM system.

Acknowledgments. This study was supported by the Climate Prediction Program for the Americas Grant GC04-033 of the National Oceanic and Atmospheric Administration Office of Global Programs. The authors thank Drs. Alan Shapiro and Michael Richman of the School of Meteorology for their assistance during this research project and Dr. Wayne Higgins for providing the CPC precipitation dataset. Three anonymous reviewers are thanked for providing constructive and helpful comments that improved the manuscript. Funding was provided by NOAA/Office of Oceanic and Atmospheric Research under NOAA-University of Oklahoma Cooperative Agreement NA17RJ1227, U.S. Department of Commerce.

\section{REFERENCES}

Adams, J. L., and D. J. Stensrud, 2007: Impact of tropical easterly waves on the North American monsoon. J. Climate, 20, 1219-1238.

Berry, G., and C. Thorncroft, 2005: Case study of an intense African easterly wave. Mon. Wea. Rev., 133, 752-766.

,-- , and T. Hewson, 2007: African easterly waves during 2004-Analysis using objective techniques. Mon. Wea. Rev., 135, 1251-1267.

Bordoni, S., and B. Stevens, 2006: Principal component analysis of the summertime winds over the Gulf of California: A gulf surge index. Mon. Wea. Rev., 134, 3395-3414.

—, P. E. Ciesielski, R. H. Johnson, B. D. McNoldy, and B. Stevens, 2004: The low-level circulation of the North American monsoon as revealed by QuikSCAT. Geophys. Res. Lett., 31, L10109, doi:10.1029/2004GL020009.

Brenner, I. S., 1974: A surge of maritime tropical air-Gulf of California to the southwestern United States. Mon. Wea. Rev., 102, 375-389.

Burpee, R. W., 1972: The origin and structure of easterly waves in the lower troposphere of North Africa. J. Atmos. Sci., 29, 77-90.

_ 1974: Characteristics of North African easterly waves during the summers of 1968 and 1969. J. Atmos. Sci., 31, 1556-1570.

Charba, J. P., A. W. Harrell III, and A. C. Lackner III, 1992: A monthly precipitation amount climatology derived from published atlas maps: Development of a digital database.
TDL Office Note 92-7, 20 pp. [Available from TDL Office, NOAA, U.S. Department of Commerce, 1325 East-West Highway, Silver Spring, MD 20910.].

Chen, T. C., 2006: Characteristics of African easterly waves depicted by ECMWF reanalyses for 1991-2000. Mon. Wea. Rev., 134, 3539-3566.

Chen, W. Y., 1982: Fluctuations in Northern Hemisphere $700 \mathrm{mb}$ height field associated with the Southern Oscillation. Mon. Wea. Rev., 110, 808-823.

Cressman, G. P., 1959: An operational objective analysis system. Mon. Wea. Rev., 87, 367-374.

Douglas, A. V., and P. J. Englehart, 2007: A climatological perspective of transient synoptic features during NAME 2004. J. Climate, 20, 1947-1954.

Douglas, M. W., 1995: The summertime low-level jet over the Gulf of California. Mon. Wea. Rev., 123, 2334-2347.

— California: Aspects of their climatology, mean structure, and evolution from radiosonde, NCEP reanalysis, and rainfall data. Wea. Forecasting, 18, 55-74.

- R. A. Maddox, K. Howard, and S. Reyes, 1993: The Mexican monsoon. J. Climate, 6, 1665-1677.

— , A. Valdez-Manzanilla, and R. Garcia Cueto, 1998: Diurnal variation and horizontal extent of the low-level jet over the northern Gulf of California. Mon. Wea. Rev., 126, 20172025.

Farfan, L. M., and J. A. Zehnder, 2001: An analysis of the landfall of hurricane Nora (1997). Mon. Wea. Rev., 129, 2073-2088.

Fink, A. H., D. G. Vincent, P. M. Reiner, and P. Speth, 2004: Mean state and wave disturbances during phase I, II, and III of GATE based on ERA-40. Mon. Wea. Rev., 132, 1661-1683.

Fuller, R. D., and D. J. Stensrud, 2000: The relationship between tropical easterly waves and surges over the Gulf of California during the North American monsoon. Mon. Wea. Rev., 128, 2983-2989.

Fyfe, J. C., 1999: Climate simulations of African easterly waves. J. Climate, 12, 1747-1769.

Glahn, H. R., T. L. Chambers, W. S. Richardson, and H. P. Perrotti, 1985: Objective map analysis for the local AFOS MOS Program. NOAA Tech. Memo. NWS TDL 75, 34 pp. [Available from TDL Office, NOAA, U.S. Department of Commerce, 1325 East-West Highway, Silver Spring, MD 20910.].

Gutzler, D. S., 2004: An index of interannual precipitation variability in the core of the North American monsoon region. J. Climate, 17, 4473-4480.

Hales, J. E., 1972: Surges of maritime tropical air northward over the Gulf of California. Mon. Wea. Rev., 100, 298-306.

—, 1974: Southwestern United States summer monsoon source-Gulf of Mexico or Pacific Ocean? J. Appl. Meteor., 13, 331-342.

Higgins, R. W., and W. Shi, 2000: Dominant factors responsible for interannual variability of the summer monsoon in the southwestern United States. J. Climate, 13, 759-776.

—, and —, 2005: Relationships between Gulf of California moisture surges and tropical cyclones in the eastern Pacific basin. J. Climate, 18, 4601-4620.

_ , Y. Yao, and X. L. Wang, 1997: Influence of the North American monsoon system on the U.S. summer precipitation regime. J. Climate, 10, 2600-2622.

_ K. C. Mo, and Y. Yao, 1998: Interannual variability of the U.S. summer precipitation regime with emphasis on the southwestern monsoon. J. Climate, 11, 2582-2606. 
Y. Chen, and A. V. Douglas, 1999: Interannual variability of the North American warm season precipitation regime. J. Climate, 12, 653-680.

_ - W. Shi, and C. Hain, 2004: Relationships between Gulf of California moisture surges and precipitation in the southwestern United States. J. Climate, 17, 2983-2997.

$\mathrm{Hu}, \mathrm{Q}$., and S. Feng, 2002: Interannual rainfall variations in the North American summer monsoon region: 1900-98. J. Climate, 15, 1189-1202.

Kalnay, E., and Coauthors, 1996: The NCEP/NCAR 40-Year Reanalysis Project. Bull. Amer. Meteor. Soc., 77, 437-471.

Livezey, R. E., and W. Chen, 1983: Statistical field significance and its determination by Monte Carlo techniques. Mon. Wea. Rev., 111, 46-59.

McCollum, D. M., R. A. Maddox, and K. W. Howard, 1995: Case study of a severe mesoscale convective system in central Arizona. Wea. Forecasting, 10, 643-665.

Mo, K. C., and E. H. Berbery, 2004: Low-level jets and the summer precipitation regimes over North America. J. Geophys. Res., 109, D06117, doi:10.1029/2003JD004106.

_ cesses associated with summer floods and droughts in the central United States. J. Climate, 10, 3028-3046.

Mock, C. J., 1996: Climatic controls and spatial variations of precipitation in the western United States. J. Climate, 9, $1111-1125$.
Pasch, R. J., L. A. Avila, and J. G. Jiing, 1998: Atlantic tropical systems of 1994 and 1995: A comparison of a quiet season to a near-record-breaking one. Mon. Wea. Rev., 126, 1106-1123.

Pytharoulis, I., and C. Thorncroft, 1999: The low-level structure of African easterly waves in 1995. Mon. Wea. Rev., 127, 2266-2280.

Reed, R. J., D. C. Norquist, and E. E. Recker, 1977: The structure and properties of African wave disturbances as observed during phase III of GATE. Mon. Wea. Rev., 105, 317-333.

Rogers, P. J., and R. H. Johnson, 2007: Analysis of the 13-14 July gulf surge event during the 2004 North American Monsoon Experiment. Mon. Wea. Rev., 135, 3098-3117.

Stensrud, D. J., R. L. Gall, S. L. Mullen, and K. W. Howard, 1995: Model climatology of the Mexican monsoon. J. Climate, 8 , 1775-1794.

, - — , and M. K. Nordquist, 1997: Surges over the Gulf of California during the Mexican monsoon. Mon. Wea. Rev., 125, 417-437.

Tang, M., and E. R. Reiter, 1984: Plateau monsoons of the Northern Hemisphere: A comparison between North America and Tibet. Mon. Wea. Rev., 112, 617-637.

Thorncroft, C., and K. Hodges, 2001: African easterly wave variability and its relationship to Atlantic tropical cyclone activity. J. Climate, 14, 1166-1179.

Wilks, D. S., 1995: Statistical Methods in the Atmospheric Sciences: An Introduction. Vol. 59, International Geophysics Series, Academic Press, 467 pp. 